Negev and the Sinai. Paper presented at the colloquium "L'urbanisation de la Palestine à l'âge du Bronze ancien: Bilan et perspectives des recherches actuelles," October 20-24, Centre de Recherche Français de Jerusalem.

ROSEN, A. M. 1986. Environmental change in the Early Bronze Age of Palestine. Paper presented at the colloquium "L'urbanisation de la Palestine à l'âge du Bronze ancien: Bilan et perspectives des recherches actuelles," October 20-24, Centre de Recherche Français de Jerusalem.

ROSEN, S. A. r983a. Lithics in the Bronze and Iron Ages in Israel. Ph.D. diss., University of Chicago, Chicago, Ill. . $1983 b$. The Canaanean blade and the Early Bronze Age. Israel Exploration Journal 33:15-29.

r983c. The tabular scraper trade: A model for material culture dispersion. Bulletin of the American Schools for Oriental Research 249:79-86.

r984. Kvish Harif: Preliminary investigations at a late Neolithic site in the Central Negev. Paléorient ro: I I-I2I. . I987a. Demographic trends in the Negev Highlands: Preliminary results from the Emergency Survey. Bulletin of the American Schools for Oriental Research 266:45-58. . $1987 b$. "The potentials of lithic analysis in the Chalcolithic of the northern Negev" in Shiqmim I. Edited by T. E. Levy, pp. 295-312, 6ro-12. British Archaeological Reports International Series.

ROSEN, S. A., AND M. HAIMAN. 1985. Nahal Mitnan II (in Hebrew). Hadashot Arhkeologiyot 86:36.

ROTHENBERG, B. I972. Were these King Solomon's mines? London: Stein and Day.

ROWTON, M. 1973. Autonomy and nomadism in Western Asia. Orientalia $42: 247-58$.

- I977. Dimorphic structure and the parasocial element. Journal of Near Eastern Studies 36:181-98.

RUSSELL, K. W. 1986. The ecology and energetics of early pastoral and cereal food production in the Near East and North Africa. Ph.D. diss., University of Utah, Salt Lake City, Utah.

SER VELLO, F. 1976. "Nahal Divshon: A Pre-Pottery Neolithic B hunting camp," in Prehistory and paleoenvironments in the Central Negev, Israel, vol. r. Edited by A. Marks, pp. 349-70. Dallas: Southem Methodist University.

simm ONs, A. H. 1980. Early Neolithic settlement and economic behavior in the Western Negev desert of the southern Levant. Ann Arbor: University Microfilms.

SHERRATT, A. I98r. "Plough and pastoralism: Aspects of the secondary products revolution," in Patterns of the past: Studies in honour of David Clarke. Edited by I. Hodder, G. Isaac, and N. Hammond, pp. 26I-305. Cambridge: Cambridge University Press.

I983. The secondary exploitation of animals in the Old World. World Archaeology I 5(r):90-104.

SMITH, P., AND L. HORVITZ. I984. Radiographic evidence for changing patterns of animal exploitation in the southern Levant. Journal of Archaeological Science ir:467-75.

TCHERNOV, E., AND O. BAR-YOSEF. 1982. Animal exploitation in the Pre-Pottery Neolithic period at Wadi Tbeik, southern Sinai. Paléorient 8(2):17-37.

WEIR, S. I976. The Bedouin: Aspects of the material culture of Jordan. London: World of Islam Festival Publishing Co.

WENDORF, F., AND R. SCHILD. I980. Prehistory of the eastern Sahara. New York: Academic Press.

\section{Off-Site Pottery Distributions: A Regional and Interregional Perspective ${ }^{1}$}

\author{
JOHN BINTLIFF AND ANTHONY SNODGRASS \\ School of Archaeological Sciences, Bradford \\ University, Bradford BD7 IDP/Museum of Classical \\ Archaeology, Cambridge University, Cambridge, U.K. \\ 9 IX 87
}

Since I980 the Cambridge/Bradford Boeotian Expedition, an archaeological survey under our joint direction, has been recording the density of pre-modern surface pottery in a landscape of Central Greece (Bintliff r985, Bintliff and Snodgrass r 985). Initially our purpose was to justify quantitatively our separation of habitation sites from less permanent traces of human activity ("nonsites" or "off-site activity areas"), since, until recently, a "site" found by field survey was distinguished merely by qualitative judgement or even on purely historical grounds. Although this first aim proved realistic, we soon found that off-site pottery scatters formed an almost unbroken carpet throughout those sectors of the landscape that were amenable to human settlement and exploitation. A secondary aim, therefore, has been the elucidation of the processes that may have led to the creation and preservation of such an off-site landscape, given that the vast majority of the pottery observed belongs to the Classical Greek and Late Roman periods, with lesser contributions from prehistoric, Hellenistic to earlier Roman, medieval, and post-medieval times.

\section{THE RECORDING OF OFF-SITE DATA}

More than 40 square kilometers of rural landscape in the province of Boeotia, Central Greece, have been fieldwalked by members of the Boeotia project since I 980 . The field-walking proceeds in regular transects, with observers normally spaced at $15-\mathrm{m}$ intervals. It is assumed that ground observation is limited to a range of approximately $2 \frac{1}{2} \mathrm{~m}$ on either side of each field-walker; hence the direct coverage, in strips $5 \mathrm{~m}$ in width, amounts to one-third of the overall ground area in each transect walked. As the observers pass along their swathes, they record visible surface pottery on a hand-held counting device or clicker. At the end of each transect, individual and collective counts and an assessment of the surface visibility are recorded by team leaders; areas with unusually high counts may then be studied in greater detail

I. (c) I 988 by The Wenner-Gren Foundation for Anthropological Research. All rights reserved oor I-3204/88/2903-0008\$1.00. We are very grateful for many helpful comments in the preparation of this article from, amongst others, M. Kirkby, J. Thornes, B. Davies, D. Davidson, M. Millett, C. Haselgrove, P. J. Reynolds, T. Whitelaw, C. Gaffney, and S. Limbrey. 


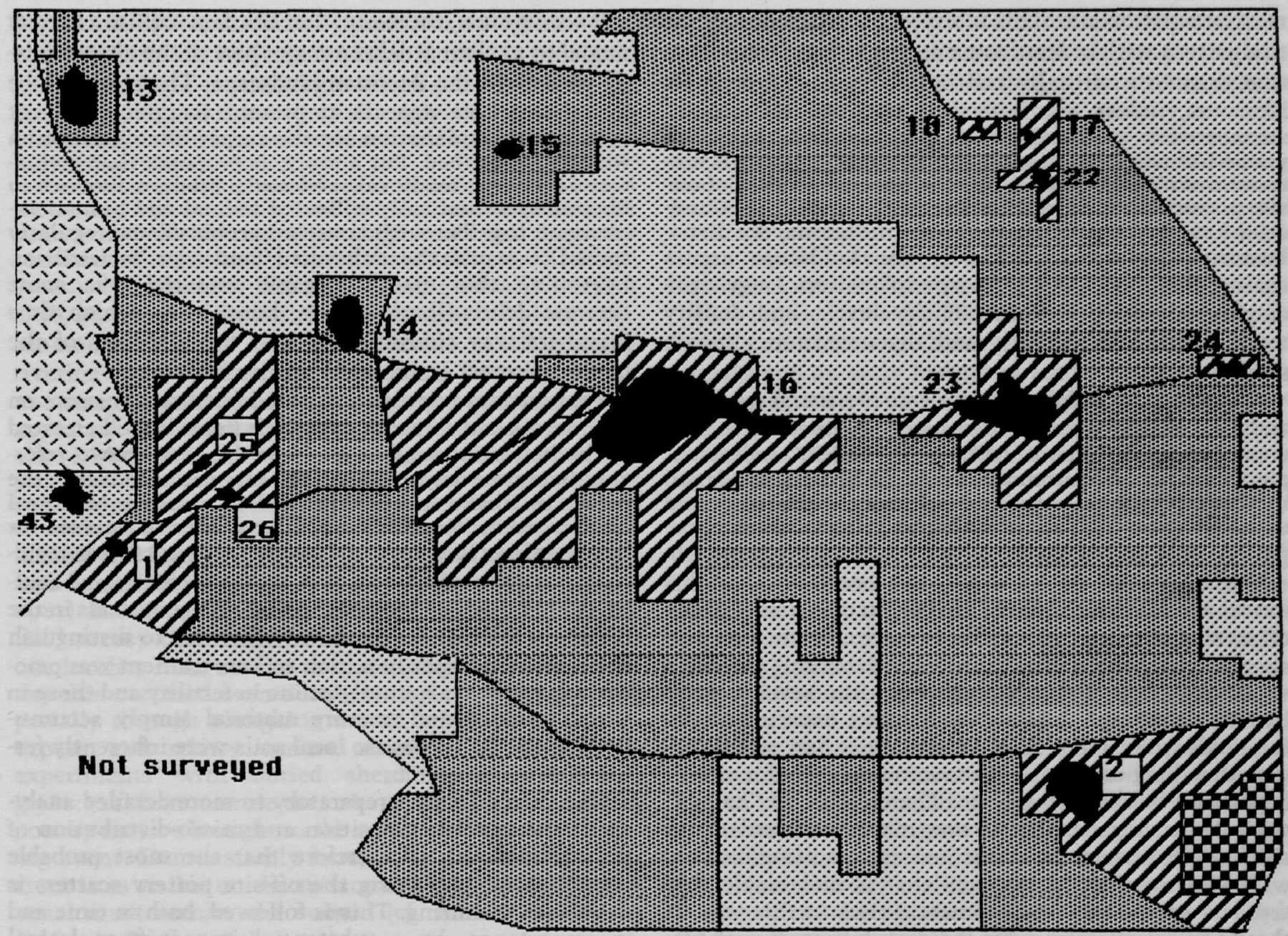

FIG. I. A typical Boeotian density plot, showing an area immediately west of the huge city site of ancient Thespiai. Solid areas, sites (with serial numbers); checkerboard, urban periphery; diagonal striping, over 600 sherds per hectare; fine dots, 100-600 sherds per hectare; wider-spaced dots, 40-100 sherds per hectare; hatching, IO-40 sherds per hectare. In the northern sector, the ground slopes steadily from north to south; in the southern, it is virtually level.

as potential "sites"; otherwise, the counts are multiplied by three and used to construct total density plots of the landscape, kilometer by kilometer (fig. I).

This surface distribution is thus an observed fact. In attempting to explain it, we pose a series of questions:

I. How did the original horizontal distribution across the landscape occur?

2. How far has displacement taken place in the vertical dimension, and through what processes?

3. What is the relationship, whether on- or off-site, between the present surface scatter and subsurface concentrations?

After offering our preferred answer to Question I, we shall raise a number of problems involved in Question 2 and then turn to an issue which bears on both this and the third question, namely, the remarkable degree of geographical variation of surface densities recorded in intensive surveys. By first attempting an explanation of this phenomenon, we hope to offer at least a regionally valid answer to these latter questions.

\section{MODELS FOR OFF-SITE SCATTERS}

One model for off-site scatters, a feature of archaeological folklore, is the mythical donkey off whose back pots are supposed to have fallen, leaving trails of sherds in otherwise unimportant zones of the landscape. Given the sheer quantity of off-site pottery and its carpet-like distribution, as well as the clear correlation of its density with proximity to occupation sites (fig. I), this model must be ruled out as a major causal explanation.

A second model, tested and found convincing in North American surveys, relates off-site scatters to activity areas less intensively used than the "normal" perma- 
nent occupation site. This interpretation is better suited to a pattern with at least some degree of local concentration than to a virtually continuous spread of artifacts like ours, unless one is dealing with special circumstances such as the discarding of projectile points in prime hunting zones (see Thomas I973). Although it is more than likely that within the Boeotian carpet of offsite pottery there exist minor activity foci whose boundaries have become blurred over the millennia, the distribution actually recorded over the landscape argues against this model as a primary explanation. Large areas display relatively uniform density levels, and density tends to decrease regularly with distance from a known site.

A third model emphasises the role of natural transport and post-depositional disturbance. Originating in discrete concentrations of artifacts, or "sites," individual pieces are removed from their context by rain, wind, and incidental human activity (especially ploughing) and smeared across the landscape intervening between occupation sites and other activity loci. Commonsense observation of surface finds on sites confirms that this model accounts for some contribution of artifacts to the off-site sphere, and experiments have shown that potsherds planted in the immediate subsoil undergo significant lateral displacement within several years (Ammermann r 985 ). However, current experiments by Reynolds ( 1982 and personal communication, I987) suggest that long-term lateral movement beyond a site of deposition is likely to be rare. The creation of "haloes" with decreasing density as one moves outwards from sites might perhaps be connected, in this same fashion, with site weathering. But whilst it is undeniable that artifacts spread out from domestic sites in this way, it should be equally clear that the distribution of such offsite material ought to be highly preferential in landscape context. Pottery eroding from a site should have minimal upslope distribution, particularly at any distance from the supposed source, and barriers to long-distance movement should be common enough to prevent site material from reaching every sector of a settled landscape. Furthermore, it has been argued that surface pottery undergoes regular stress from natural and human activity that should reduce long-exposed and muchtravelled pieces to a highly worn and fragmented condition. The Boeotian off-site material, from our preliminary investigations, demonstrates clear contradictions of these predictions. The off-site carpet stretches across the landscape, ignoring natural barriers to movement from known sites; there is plentiful material found upslope from existing sites and beyond the reasonable scope of ploughing smears; there is no regular distinction in quality of preservation between sherds found within a site and sherds from outlying quarters of the landscape. That the off-site pottery does tend to be more heavily concentrated downslope from known sites (Reynolds I982:325), whilst conceivably reflecting a locational preference for an occupation site above an area of concentrated human activity, does, however, more plausibly reflect the influence of downslope transport.
It seems clear, therefore, that the data require a further model to explain at least a major part of the characteristic pattern in the Boeotian landscape. The model to be introduced here appears at present to offer the most satisfactory explanation for the carpet-like distribution we have described. Put simply, it proposes that prehistoric, ancient, medieval, and early modern farmers in Boeotia systematically collected animal and human excrement, together with household rubbish, and regularly spread it across the cultivated landscape as fertiliser. Leavening this mainly organic material was some ceramic debris-broken pots, house tile-which thus found its way continuously into those sectors of the landscape most assiduously cultivated.

That ancient populations stored fertilising manure on their farms and spread it over their fields is well attested in the historical sources (perhaps the best-known reference being the description of the manure heap beside the palace in Ithaka in Book 17 of the Odyssey). Medieval landscapes in Western Europe have been recognised for some time as having been covered with potsherds residual from night-soil disposal. A recent sophisticated analysis of historic and prehistoric anthropogenic soils in the Northern Isles of Scotland has been able to distinguish between landscapes in which soil enrichment was practised to counter a natural decline in fertility and those in which midden and manure material simply accumulated at the farm because local soils were inherently fertile (Davidson I986).

Our current view, preparatory to more detailed analysis of the exact composition and micro-distribution of off-site material, is therefore that the most probable prime factor underlying the off-site pottery scatters is deliberate manuring. This is followed, both in time and in importance, by a substantial impact from lateral transport, especially downslope, of weathering products by both nature and the plough. Lesser contributions will have come from temporary activity areas, vestigial domestic sites, and casual artifact loss. Whether the reader accepts this relative ranking as reasonable or would prefer to alter the order of significance, the existence of the pottery carpet is an undoubted and striking feature of the "fossil landscape" that is worthy of more detailed attention for other reasons and, indeed, in its own right.

\section{EROSIONAL HISTORY AND SURFACE POTTERY}

From a combination of empirical experiment and theory, Kirkby and Kirkby (1976) suggested that abandoned habitation sites underwent a series of processes on different time-scales. Initially, decay produced an abundance of material on the surface, but in the medium to long term this surface pottery suffered progressive attrition. Human and animal movement across a former site comminuted sherds, and the physical nature of the pottery made it very susceptible to stresses (induced by exposure to varying degrees of warmth and moisture on and within the soil) that hastened the break-up of pot 
fragments. Kirkby and Kirkby predicted a progressive attack on potsherds with age (see also Reynolds I982:3 I6) and, assuming a continual growth in soil depth over the landscape, argued that eventually only a tiny proportion of the original surface collection would remain unburied for surface observation.

From this study, it would seem to follow that sites of increasing age would become less and less visible on the surface and the pottery more fragmented and in poorer condition. But it must be noted that Kirkby and Kirkby's assumed progressive soil increment, gradually burying sites, was derived from fieldwork in alluvial plain environments and may not be applicable at all to nonriverine zones such as the hill-land of Boeotia whence our sample emanates. Yet although the progressive disappearance of surface pottery into the subsoil owing to alluvial burial is not everywhere appropriate, other empirical studies have shown that surface sites nonetheless suffer appreciable downward loss of artifacts as a result of such processes as the burrowing activities of soil macro- and microfauna and pressure exerted by human and animal movement over the surface (Hemingway I98I). Indeed, it is widely attested by practitioners of field survey that surface sites appear and disappear in one locality from season to season; for the Boeotia survey this occurred even during a single field season (especially through ploughing events, which can both reexpose and rebury surface sites). Peter Reynolds's experiments with buried sherd replics at Butser (I982:322) demonstrate that I6-I7\% of the total subsoil pottery may be brought to the surface after each ploughing event. Demonstrably here, and undeniably for ancient sites visible on the surface today, most of this material must reenter the subsoil (cf. similar results for lithics in Frink 1984).

Recent work by Thornes in south-eastern Spain (Thornes and Gilman 1983, Gilman and Thornes I985) has opened up a major new perspective on surface pottery by concentrating on the changing nature of the soil matrix. Thornes argues that, while the geomorphology of the Mediterranean landscape suggests continual severe erosion, this impression is very misleading, as the lines of plateaux, hillslopes, and valleys have remained little changed during the Holocene era and are relicts of earlier weathering processes. Exceptions to this generalisation are highly mobile sectors involving cliff retreat and upward migration of stream headwaters. But if the shape of landforms is relatively stable over millennia, the opposite is true of the thin coating of weathering products overlying the landforms-the regolith or soil cover. Here Thornes's detailed research suggests a dramatic instability during the Holocene. Once cleared of natural vegetation, Mediterranean soils show a wide range of susceptibility to natural erosion. Amongst the most easily eroded are marls and sandstones of marine or lacustrine origin, sediments whose soils have proved to be highly favoured for prehistoric and ancient farming (Bintliff r 977). The commonest soil type underlying the surface pottery carpet in Boeotia is just such a sediment. Here once again, however, Thornes's findings contrast with traditional views, for he maintains that current annual weathering rates are neither high nor particularly damaging to the regolith. Rather, it is extreme erosion events, occurring at intervals of a century or more, which are responsible for major phases of erosion across the landscape. The fact that large areas of the Mediterranean lands are currently covered by soils of an immature profile $(\mathrm{A}[\mathrm{B}] \mathrm{C}, \mathrm{A} / \mathrm{C}$, or even $\mathrm{C})$ is, he would argue, the result of truncated development brought about by extreme rainfall events, which worked differently on highly susceptible lithologies.

The implications of Thornes's Spanish research for Boeotia are clear-cut. Given the nature of the soils and climate and an early history of land clearance, we may confidently infer recurrent phases of soil erosion to have taken place since Bronze Age times, with a recurrent truncation of the soil profile. In contrast, therefore, to Kirkby and Kirkby's model situation of positive soil increment over sites, we must now consider the effects on surface densities of cycles of topsoil stripping.

Recent research on the erosional history of the Greek landscape fits surprisingly well with Thornes's predictions. The most important advance came in I980, with the appearance of a well-documented regional study of the changing environment of Attica by a Belgian team (Paepe, Hatziotis, and Thorez I980). Careful geomorphological and pedological studies, combined with archaeology and history, showed a series of cycles during the main phases of farming exploitation (from Bronze Age to present), consisting of lengthy periods of landscape stability (soil growth and maintenance) punctuated by short phases of landscape instability (soil loss and river alluviation). Paepe and his team correlated these cycles with secular changes of climate. Remarkable confirmation for the Attic sequence has now appeared from a regional landscape study in the Argolid peninsula (Pope and Van Andel r984). A virtually identical sequence of stable and unstable phases is documented with the same chronology as in Attica. The American Argolid team, however, minimises the importance of climatic fluctuations, postulating instead that phases of intense erosion are associated with depopulation and neglect of terraces. It is certainly striking that such times of destabilisation of the landscape succeed apparent population peaks, such as the Early Bronze Age, the Classical era, and the Late Roman era, but the absence of a corresponding event after the collapse of the Mycenaean (Late Bronze Age) civilisation is a serious flaw in the argument.

For the purposes of this paper, it is not necessary to pursue in detail this fascinating question of processes, since our prime concern is to confirm the strong likelihood of regular soil truncation and redeposition in the long-settled landscape of Boeotia. Whatever solution we propose, likewise, for the similarly unresolved question of the origin of surface pottery carpets, we must accept the probability that present surface distributions also bear the imprint of one or more severe erosional phases, in which a significant part of the soil matrix has been removed from its original location. 


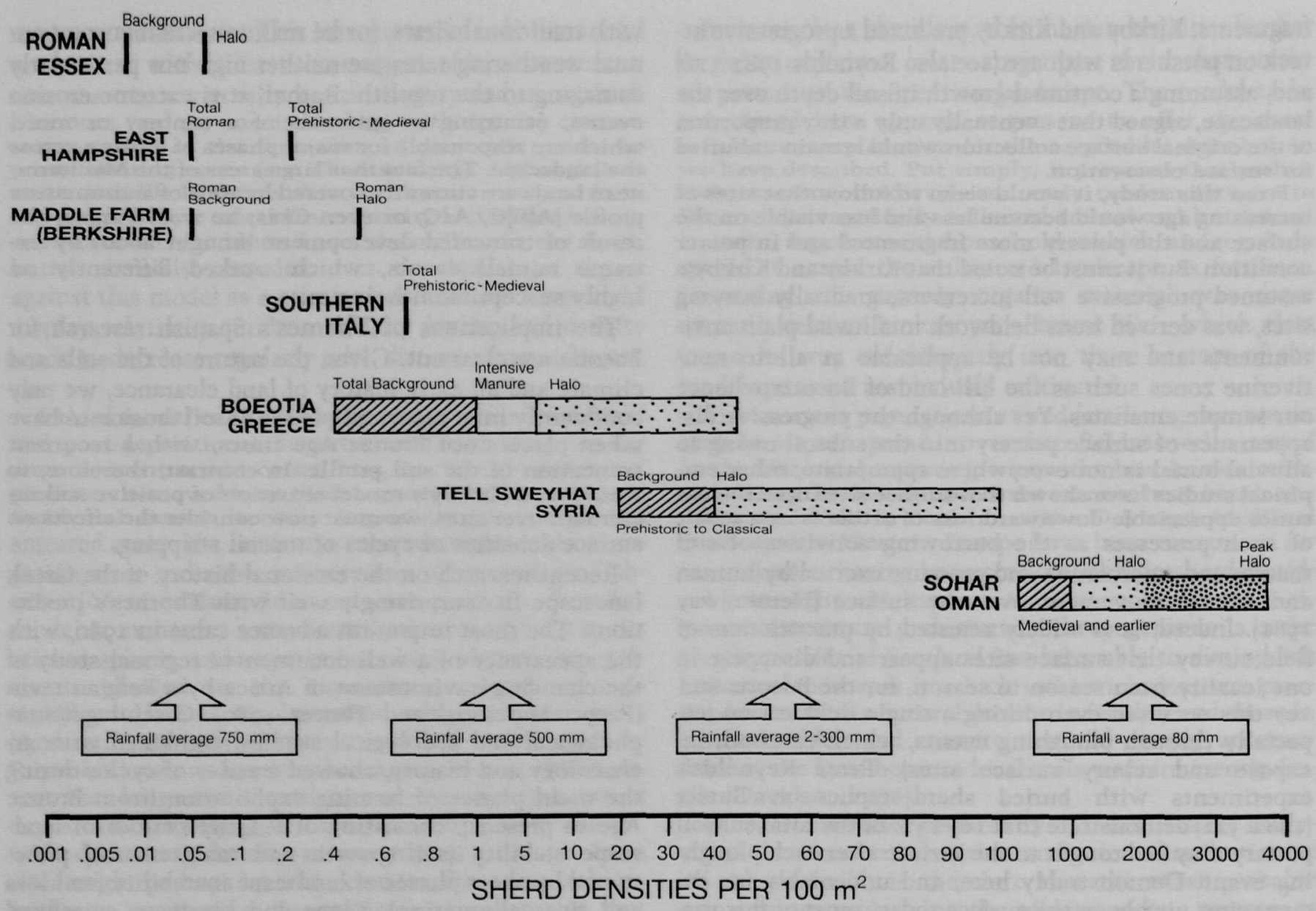

Fig. 2. Sherd densities per $100 \mathrm{~m}^{2}$ at a sample of sites. Roman Essex, background 0.8 , site haloes 4 or more per hectare (Williamson 1984:228 and fig. 2); East Hampshire, for a walked strip I0o $\mathrm{m}$ long and $2 \mathrm{~m}$ wide, Roman finds o. $\mathrm{I}$, total prehistoric-to-medieval $0.2 \mathrm{I}$ per $200 \mathrm{~m}^{2}$ (Shennan $x 985: 75,8 \mathrm{I}, 9 \mathrm{I}$, and personal communication; figures seem to include portions of sites bisected by transects); Maddle Farm, Berkshire, background 0.05, halo 0.5 per $100 \mathrm{~m}^{2}$ (Gaffney and Tingle 1985; Gaffney, personal communication); southern Italy, 0.007 per $\mathrm{m}^{2}$ on a transect system for all periods, though it seems that prehistoric and Classical predominate (Hodder and Malone I984:I27, table I; figure seems to include portions of sites bisected by transects); Boeotia, Bintliff and Snodgrass (I985); Tell Sweyhat, background 20-40, halo 40-I00+ per $100 \mathrm{~m}^{2}$, finds predominantly prehistoric and Hellenistic (Wilkinson 1982:328); Sohar, average 2.5-10, peak 37.5 per $\mathrm{m}^{2}$ (Wilkinson 1982:328).

\section{OFF-SITE SURFACE POTTERY: A COMPARATIVE} ANALYSIS

Off-site surface pottery densities are still not regularly being recorded in Old World field surveys, and the small comparative sample here reviewed is in any case not intended to be complete. Nonetheless, there does appear to be a highly consistent pattern (fig. 2) in absolute values, which fits a cline running from England through Italy to Greece and then via Syria to Oman. In simple terms, the density of off-site pottery increases steeply from temperate north-western Europe through the Mediterranean to the Middle East. ${ }^{2}$

2. The recent study by Gallant ( 1986 ) of off-site pottery in the Ionian Islands off the west coast of Greece demonstrates phenomena identical to those discussed from Boeotia in this paper. Gal-
An initial query must relate to the homogeneity of the data. In chronological terms, this is certainly not present, as the data plotted represent both single-period and multiperiod scatters, scatters primarily prehistoric, Roman, medieval, or all of these. Yet it is difficult to argue that such variability explains the cline of density. In England, for example, the density of surface pottery of all periods in the East Hampshire survey clusters closely with the density of Roman pottery from the same survey, which in turn clusters with Roman pottery densities in Essex and Berkshire. Certain of our sites in Boeotia are, with their peripheries, also essentially one-

lant's off-site "background" density of pottery for all periods (p. 4I7) is 8 to 15 per $100 \mathrm{~m}^{2}$, comparable to the denser end of off-site densities in Central Greece (cf. our fig. 2). 
period Roman sites and so may be fairly compared with these. Again, primarily prehistoric density around Tell Sweyhat in Syria is far higher than even multiperiod densities in Italy and Greece but is in turn eclipsed by medieval scatters in Oman.

It may be noteworthy that the three English surveys show a tendency for increased sherd densities associated with lithologies of greater susceptibility to erosion. The Essex data stem predominantly from Boulder Clay, whereas the East Hampshire data base includes a significant sector of Chalk. The Maddle Farm data come entirely from Chalk downland. We are grateful to John Thornes for the suggestion, based on his own researches in the Mediterranean (see Gilman and Thornes I985), that a corollary of a climate/vegetation cline for surface exposure of pottery might be a cline of pottery density within each region reflecting geological and pedological controls over susceptibility to erosion.

Although common sense suggests that there will be measurable variability in all regions according to the length of human occupation and its scale of activity in the landscape-indeed, where scatters can be subdivided by period, as in East Hampshire, this is demonstrablethe underlying trend is clearly interregional and not chronological.

Martin Millett and Colin Haselgrove have suggested (personal communication) that one probable independent and regionally distinct factor is the rate of pottery supply and pottery consumption per unit of settled landscape. In this model, peripheral England would have had a poorer pottery supply system and rural sites would characteristically employ much smaller assemblages of pottery by comparison with Greece and Italy, and the same would hold for comparisons between the latter and the Middle East. Whilst this factor cannot be ignored, the following considerations weaken its significance. First, relative pottery supply and use would need to follow an almost unchanging cline across these vast distances of space and time, beginning with prehistoric Syria and extending to medieval Oman. But more damaging to this explanation is the element of scale operating along the density cline: whereas it might be reasonable, for the sake of argument, to postulate that a Roman farmer in Central Greece had twice as many pots as his counterpart in Roman Essex, the actual multiplier required to elevate the upper range of English densities to the lower part of the corresponding range in Greece is Io. The multiplier required from Boeotia to Syria, for general background scatter, is a further 4 , while the Boeotian densities must be multiplied by 177 to reach the lower end of the Oman scatters. The whole range, from England to Oman, requires a multiplier of 1,500 !

Although each of these considerations deserves further, more detailed examination, we feel that the fundamental regularity and scale of this cline cannot be explained adequately by any of them. A far more promising avenue lies in geographical variability. The density cline correlates with annual rainfall and temperature (fig. 2). One might argue that temperate north-western Europe would be an ideal environment for humus development and the progressive burial of pottery by increased soil depth, whilst further south and east, conditions for soil increase would become increasingly unfavourable. Although this observation is in general correct, the rate of soil growth in Britain is in fact so slight on average that, even over millennia, burial by direct soil overgrowth is unlikely to be a major factor in surface pottery availability. Infiltration of artifacts into the subsoil by incidental processes, whether natural or human in origin, is, as we have said, likely to be important in all regions, but it can be shown that conditions for the burial of small artefacts such as potsherds are increasingly favourable as we move along the climatic cline from the Middle East to north-western Europe. The moister, less extreme climates promote a more vigorous soil fauna, whose activity within the soil tends overall to sift through the surface and subsurface and thereby levigate artefactual inclusions downward through the soil profile. Especially potent in temperate climates is earthworm activity, and indeed it was Darwin's work on Roman and other ruins in England that demonstrated the power of these humble creatures: "Archaeologists are probably not aware how much they owe to worms for the preservation of many ancient objects. Coins, gold ornaments, stone implements, etc., if dropped to the surface of the ground, will be buried by the castings of worms in a few years, and thus be safely preserved" (Darwin I896:176, quoted in Wood and Johnson I978). Hofman (1986) provides figures for stone tool vertical displacement of $20-40 \mathrm{~cm}$ in temperate environments over periods of $7,000-9,000$ years. More arid environments produce far slower rates (Terra Amata in Mediterranean France has data suggesting an average of $40 \mathrm{~cm}$ displacement over $200,000-$ 400,000 years; northern Kenya produces evidence of up to $50 \mathrm{~cm}$ displacement over 1.56 million years). However, as S. Limbrey has pointed out (personal communication), these figures should not be taken to imply constant downward movement of artefacts over such long time-periods. There is likely to be an exponential fall in the rate of movement and a limiting depth to the activity of much of the relevant soil fauna. It is possible that the current basal positions of displaced artefacts were established over much shorter time-spans.

If we turn to the opposite tendency, soil stripping, we have an even more promising picture. The average values for normal erosion rise from temperate environments to a peak in areas with $200-300 \mathrm{~mm}$ of rainfall (based on observations in the American Southwest [Langbein and Schumm 1958]), where aridity is combined with storm violence and a low degree of vegetative protection. We can therefore predict that soil stripping would become increasingly important along our cline from England to Syria (peak erosion conditions). In regions with lower rainfall-and here Oman, with $80 \mathrm{~mm}$, is well below the erosion peak-water erosion is extremely limited. But for Oman, Wilkinson (I982) has argued that the highly arid soils undergo massive wind deflation.

As our working hypothesis we would therefore suggest that the most significant factors underlying the ap- 
parent cline in off-site pottery densities are differential soil erosion, which is exposing ever greater amounts of subsoil pottery in semi-arid areas, in proportion to the intensity of soil loss, and differential soil levigation, which is burying surface and subsurface artefacts in temperate areas.

We are led immediately to ask how, in the first place, the pottery visible found its way into the subsoil, if we have already had to limit the role of natural burial for many areas. For one thing, some pottery originates from site reservoirs, especially rubbish pits, cellars, etc. Here differential soil loss should reveal differential surface densities. This aspect of the problem, at least, should be susceptible to empirical testing: where an intensively surveyed locality is later subjected to excavation, full recording of sherd densities by both surveyor and excavator should make it possible to establish a ratio between surface and subsoil densities. The surface density might then be expressed in terms of a "deposit value" namely, that depth of soil whose sherd content proved to correspond, in absolute yield, with the amount previously visible on the surface of exactly the same piece of ground.

This mode of proceeding has not yet, to our knowledge, been reported, at least from anywhere in Mediterranean lands, but some interesting data are shortly to become available from the Kea Survey; here the Neolithic site of Kephala, previously excavated by John E. Coleman with a fairly detailed recording of pottery yields, was subjected to later intensive survey. The factors are obviously more complicated here than those that would operate with the reverse sequence. Nevertheless, the survey yielded surprisingly high surface densities, both of pottery and of obsidian, at this location. At least in the areas of the most extensive trenches of Coleman's excavation, some consistent trends in the ratio of pottery to obsidian, on and below the surface, and in the ratio of surface densities in both materials could be observed. Todd $\mathrm{M}$. Whitelaw offers the provisional estimate that the surface densities, averaged out to eliminate the more highly localised anomalies, might correspond to "perhaps IO-20 cm's worth" of deposit (personal communication; we are very grateful to Whitelaw and to John F. Cherry, joint director of the survey, for allowing us to make use of these observations). This at least gives a pointer to the order of magnitude of soil loss that might be expected to have occurred, over some five or six millennia, on an Aegean island site. Again, at the site of Asteri/Karaousi, in southern Laconia, surface reconnaissance /Waterhouse and Hope-Simpson 1960:89-92) gave plentiful prehistoric sherds, from Neolithic to Late Bronze Age in date. Subsequent trial trenching (Taylour 1972:262-63) met bedrock at $50-70 \mathrm{~cm}$ depth and meagre artefactual and structural remnants. The site is an exposed hill on which erosion would be predictably high.

Pottery smeared out from sites by weathering would also follow a cline of density by erosion values. But if, as we have argued, much of the off-site pottery has been spread by man over the landscape in the manuring process, it might at first sight seem that all regions would begin with comparable surface densities off-site, and the amount of soil loss would be irrelevant here. It has been pointed out (see Jameson I978), however, that manuring is of limited value unless the fertiliser is ploughed into the soil: if it is not, the organic nutrients will oxidise and be lost to plant roots. We can therefore expect a continual pushing into the subsoil of surface additions, which, when added to the further internal processes of migration downwards and laterally, will have created, under stable soil conditions, a pottery reservoir that is predominantly located in the subsoil. It is the phases of instability, especially events such as those described by Thornes, that see the potent differential effects of soil stripping acting to differentiate visible surface densities and hence create our density cline.

A final question remains: if the soil matrix in Mediterranean soils undergoes cyclical displacement, what exactly happens to its sherd content? Clearly, since the pottery carpet is as prevalent on watersheds as on lower slopes, the pottery does not simply get washed away with the fines. Kirkby and Kirkby (1976) argue for a process of "lagging" whereby the fine soil particles are washed away but the heavier items (stones, pottery) remain in position (leaving so-called armoured surface soil). When soil growth begins again and persists, if it has a chance to, for long periods (as often appears to be the case), the "lagged" deposit is reincorporated into a new soil matrix and pushed downwards over time by man and nature. This process of soil recovery is in any case chiefly downwards by bedrock weathering, with only slight increment from humus accumulation at the top of the profile.

However, the success of field-resistivity and magneticsusceptibility measurements in Greek palaeolandscapes such as the Boeotia Survey region may suggest that, in contrast to the total or all-but-total soil replacement outlined earlier for erosion cycles, a significant amount of the original soil has been left in situ. This conclusion conforms better to current understanding of rates of soil growth (S. Limbrey, personal communication), which is a very slow process in the semi-arid environment in which lag deposits are predominant. It also agrees with the conclusions of Reynolds (1982:334) regarding the preservation of the subsoil over millennia.

Without demonstrating a single, undeniable explanation for the pattern visible, we have tried to open up for discussion some intriguing questions. In the next few years, many further surveys will doubtless be published with off-site information that will serve to test and refine our suggested explanations.

\section{References Cited}

A M MERMANN, A. T. I985. Plow-zone experiments in Calabria, Italy. Journal of Field Archaeology 12:33-40.

BIN TLIFF, J. L. r977. Natural environment and human settlement in prehistoric Greece. British Archaeological Reports International Series 28.

- I985. "The Boeotia Survey, Central Greece," in Archaeo- 
logical field survey in Britain and abroad. Edited by S. Macready and F. H. Thompson, pp. 196-216. London: Society of Antiquaries.

BINTLIFF, J. L., AND A. M. SNODGRASs. I985. The Boeotia Survey, a preliminary report: The first four years. Journal of Field Archaeology 12:123-61.

DA VIDSON, D. A. 1986. "Anthropogenic soils and landforms in Orkney," in Essays for Professor R. E. H. Mellor. Edited by W. Ritchie et al. Aberdeen: University Press.

DARWIN, C. I 896. The formation of vegetable mould through the action of worms. New York: Appleton.

FRINK, D. S. I984. Artifact behaviour within the plow zone. Jour nal of Field Archaeology I I:356-63.

GAFFNEY, v., AND M. TINGLe. I985. "The Maddle Farm (Berks.) Project and micro-regional analysis," in Archaeological field survey in Britain and abroad. Edited by S. Macready and F. H. Thompson, pp. 67-73. London: Society of Antiquaries.

GALLANT, T. W. I986. "Background noise" and site definition: A contribution to survey methodology. Journal of Field Archaeology I3:403-I8.

GILMAN, A., AND T. B. THORNES. I985. Land use and prehistory in south-east Spain. London: Allen and Unwin.

HEMINGWAY, M. I981. Observations on the length and breadth measurements of whole flakes from the Hermitage Rock Shelter. Sussex Archaeological Collections I I9:30-36.

HODDER, I., AND C. MALONE. I984. Intensive survey of prehistoric sites in the Stilo region, Calabria. Proceedings of the Prehistoric Society 50:12 I-50.

HOFMAN, T. I986. Vertical movement of artifacts in alluvial and stratified deposits. CURRENT ANTHROPOLOGY 27:163-71.

JAMESON, M. H. I978. Agriculture and slavery in Classical Athens. Classical Journal 73: 122-45.

KIRKBY, A., AND M. J. KIRKBY. I976. "Geomorphic processes and the surface survey of archaeological sites in semi-arid areas," in Geoarchaeology. Edited by D. Davidson and M. Shackley, pp. 229-53. London: Duckworth.

LANGBEIN, W. B., AND S. A. SCHUMM. I958. Yield of sediment in relation to mean annual precipitation. Transactions of the American Geophysical Union 39:1076-84.

PAEPE, R., M. E. HATZIOTIS, AND J. THOREZ. 1980. Geomorphological evolution in the eastern Mediterranean belt and Mesopotamian plain. (International Geological Correlation Programme, Project I46: River Flood and Lake Level Changes.) MS.

POPE, K. O., AND T. H. VAN ANDEL. I984. Late Quaternary alluviation and soil formation in the southern Argolid: Its history, causes, and archaeological implications. Journal of Archaeological Science II:28I-306.

REYNOLDS, P. T. I982. "The ploughzone," in Festschrift zum roojahrigen Jubiläum der Abteilung Vorgeschichte der Naturhistorischen Gesellschaft Nurnberg, pp. 31 5-40. Nurnberg.

SHENNAN, s. 1985. Experiments in the collection and analysis of archaeological survey data: The East Hampshire Survey. Sheffield: Department of Archaeology and Prehistory.

TAYLOUR, W. D. I972. Excavations at Ayios Stephanos. Annual of the British School of Archaeology at Athens 67:205-70.

THOMAS, D. H. 1973. An empirical test for Steward's model of Great Basin settlement patterns. American Antiquity 38: 15576.

THORNES, J. B., AND A. GILMAN. I983. Potential and actual erosion around archaeological sites in south-east Spain. Catena suppl. 4:9 I-II3.

WATERHOUSE, H., AND R. HOPE-SIMPSON. I960. Prehistoric Laconia. Part I. Annual of the British School of Archaeology at Athens 55:67-107.

WILKINSON, T. J. I982. The definition of ancient manured zones by means of extensive sherd-sampling techniques. Iournal of Field Archaeology 9:232-333.

Williamson, T. M. I984. The Roman countryside: Settlement and agriculture in N.W. Essex. Britannia 15:225-30.

WOOD, W. R., AND D. L. JOHNSON. I978. A survey of disturbance processes in archaeological site formation. Advances in Archaeological Method and Theory I:3I 5-8I.

\section{Prehistoric Exchange across the Vitiaz Strait, Papua New Guinea ${ }^{1}$}

\section{AN LILLEY}

Department of Anthropology and Sociology, University of Queensland, St. Lucia, Qld. 4067, Australia. 2 x 87

This paper summarizes some of the major results of archaeological research into the origins and evolution of the Siassi trading system (Lilley I986), which at the time of European contact spanned the Vitiaz Strait to link northeastern New Guinea with the Bismarck Archipelago (Harding 1967) (fig. I).

The investigations focussed on one site on each of Tuam and Malai Islands in the Siassi group and another at Sio on the New Guinea mainland. Much of the analysis of excavated cultural material examined changes in the stylistic and petrological characteristics of pottery. Attention was also paid to aspects of the stone artefact assemblages, particularly variations in the quantities, qualities, and sources of obsidian, as well as the shell and bone artefact assemblages and faunal recoveries.

If the sequences from the three sites are amalgamated, a culture-historical model of the development of regional exchange networks can be suggested (fig. 2). As Harding surmised (pp. 238-4I), the earliest evidence for long-distance exchange in the Vitiaz Strait region dates to the time of the development and spread of Lapita pottery (for an overview of the Lapita cultural complex, see Green I979; see also Pawley and Green I984, 1973). The Lapita presence in the Siassi Islands may have been only intermittent, as very little cultural material from this period was recovered. Fragmentary though they are, the remains do suggest that the nature and range of activities pursued at that time are broadly similar to those recorded in the area by Harding and others. Pottery, obsidian, and probably pigs and horticultural products were imported, while the exploitation of local marine resources focussed on inshore fishing and shellfish gathering.

That, however, is where the similarities end. Although petrological analysis of pottery hints at limited cross-Strait activity during the Lapita phase, there is no evidence for two-way communication, the cross-Strait movement of anything other than pottery, or the involvement of Sio or any other community on the Huon

I. (c) 1988 by The Wenner-Gren Foundation for Anthropological Research. All rights reserved oOII-3204/88/2903-0009\$1.00. The research described here was a doctoral project generously supported by the Department of Prehistory, Research School of Pacific Studies, Australian National University. I am indebted to Jim Allen, Jack Golson, Roger Green, Geoff Irwin, Pat Kirch, Jim Specht, and Doug Yen for their careful scrutiny of my work. Win Mumford and Betsy-Jane Osborne prepared the figures. I refer readers to my thesis for acknowledgment of others who assisted with the project. 